\title{
TAHSP:
}

The Internet Joưnal of Allied Health Sciences and Practice

A Peer Reviewed Publication of the College of Health Care Sciences at Nova Southeastern University

Dedicated to allied health professional practice and education

http://ijahsp.nova.edu Vol. 12 No. 1 ISSN 1540-580X

\section{Percentile Ranks for Walking Speed in Subjects 70-79 Years: A Meta-Analysis}

\author{
James Roush, PT, PhD, ATC1 \\ R. Curtis Bay, $\mathrm{PhD}^{2}$
}

1. Professor, Physical Therapy Program, A. T. Still University, Arizona School of Health Sciences, Mesa, Arizona

2. Associate Professor, Interdisciplinary Health Sciences, A. T. Still University, Arizona School of Health Sciences, Mesa Arizona

\author{
United States
}

CITATION: Roush J, Bay RC. Percentile Ranks for Walking Speed in Subjects 70-79 Years: A Meta-analysis. The Internet Journal of Allied Health Sciences and Practice. Jan 2014. Volume 12 Number 1.

\section{ABSTRACT}

It has been suggested that walking speed is the sixth vital sign. To adequately assess the status of walking speed of patients, normative data or percentile ranks are required. The purpose of this study was to develop percentile ranks for walking speed using a meta-analytic approach for independent, community-dwelling males and females between 70 and 79 years of age. Using PubMed and CINAHL, articles were included in the analysis if: 1) subjects were between 70 and 79 years of age; 2) "walking speed" was described as "comfortable," "preferred," "usual," "normal," or "self-selected"; 3) subjects were classified as independent and community-dwelling; 4) data were provided separately for males and female; 5) means, standard deviations (SD) and sample size were presented or easily discerned; and 6) the English language was used. Two systematic reviews (Bohannon and Andrews, Rydwik et al) were also used to help identify relevant studies. Articles were not included if the sampling methods or testing protocol were not well described by the authors. Principal author, country of study, and timing method, mean walking speed, SD, and number of subjects were obtained for each article. Weighted means, pooled SD, and percentile ranks from 5 to 95 were calculated. Samples of 6359 males from 22 studies representing 10 countries and 12064 females from 34 studies representing 12 countries were used for analysis. Minimal Detectable Changes (MDC) were also calculated for $95 \%$ and $90 \%$ confidence levels. The weighted mean walking speed was $116.72 \mathrm{~cm} / \mathrm{sec}$ (pooled SD \pm 18.77 ) for males and 105.49 $\mathrm{cm} / \mathrm{sec}$ (pooled SD \pm 21.20 ) for females. Percentile ranks from 5 to 95 were calculated for males and females. For females, the

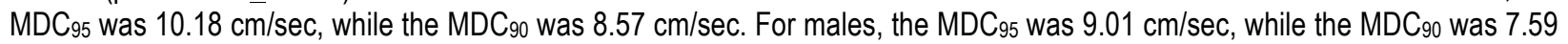
$\mathrm{cm} / \mathrm{sec}$. Percentile ranks are easy to explain and easy to understand, and may be used as adjunctive information during routine healthcare visits.

\section{INTRODUCTION}

Adequate mobility is essential for individuals to maintain an independent and active lifestyle. Because of its prevalence, decreased mobility is particularly problematic among older adults. Walking is a common means of mobility for most individuals, whether in the home or the community. The World Health Organization defined walking in its International Classification of Function as "moving along a surface on foot, step by step, so that one foot is always on the ground, such as when strolling, sauntering, walking forwards, backwards, or sideways."1 The speed at which an individual walks can be a predictive of overall function and the assistance level required in performing everyday tasks. ${ }^{2-4}$ However, data on normative walking speed values by age group are sparse.

Walking is a complex functional task that requires full body support, correct timing, power, balance and coordination. ${ }^{4}$ Walking places high demands on the brain, spinal cord, muscles, joints, lungs and heart, and requires coordination among the musculoskeletal, neuromuscular, and cardiovascular systems. ${ }^{4}$ An individual's walking speed also depends on cognition, mental health, and motivational level. ${ }^{4}$ 
Walking speed has been shown to correlate with functional ability, balance, and coordination in older adults. ${ }^{4}$ It is associated with future hospitalizations, increased risk of dependency, fall risk, increased risk of institutionalization, decreased mobility, and mortality..-47 It has recently been proposed as the sixth vital sign, along with blood pressure, heart rate, respiratory rate, pain, and temperature. 4

Researchers have found high intra- and inter-rater reliability when measuring comfortable walking speed.3,4,48 A systematic review by Rydwik et al examined the validity and reliability of walking speed distances ranging from 2 meters to 40 meters in institutionalized and community-dwelling adults ages 60 years or greater. ${ }^{3}$ Their findings suggest that comfortable walking speed is a highly reliable measure in both community-dwelling and mixed settings, such as nursing homes. ${ }^{3}$

A decrease in walking speed may provide clinicians an early warning sign of possible disruptions in one or many body systems. Early detection of decline in function can lead to early intervention for older adults, which may result in fewer hospitalizations and increased functional independence. For walking speed to have clinical relevance and applicability in the clinic, normative, reference values by age group and sex are required.

Peters et al reported the reliability and validity of walking speed measurements for the 4-meter walk test (4MWT) and the 10meter walk test (10MWT) in healthy, older adults. ${ }^{48}$ Both tests were found to have high test-retest reliability, with intraclass correlation coefficients (ICC) ranging from .96 to .98 . These authors also examined the reliability of two timing methods: stopwatch and automatic timer. Both methods had similar standard errors of measurement, between 0.04 and $0.08 \mathrm{~cm} / \mathrm{s}$. The agreement between the two methods was also high with ICC values ranging from 0.99 to 1.00 . They concluded that measurement of both the 4MWT and 10MWT were reliable and valid using either a stopwatch or automatic timer, and both testing distances rendered walking speed values with excellent agreement. However, Peters et al also noted that for clinical use, testing distances should not be used interchangeably for the same patients over time.48

References values, in the form of percentile ranks, may be calculated using the area under the Gaussian (normal) distribution. They are easy to calculate, easy to explain, and easy to understand. Minimal detectable change (MDC) is the smallest change in a score that is result of an actual change in performance and not the result of measurement error or chance. 49 It is the smallest difference in scores for repeated measures that is considered real. $50 \mathrm{MDC}$ is the product of the standard error of the measurement for a test, the critical value chosen by the investigator (usually at a significance level of .05 or .10), and the square root of two.

Researchers have focused on walking speed in populations presenting with significant gait deviations as a result of disease or trauma such as Parkinson's disease, cerebral vascular accidents, Alzheimer's disease, and post-hip surgery. Little of the literature, however, is applicable to healthy, community-dwelling older adults. The purpose of this meta-analysis was to identify data on comfortable walking speed in individuals aged 70 to 79 years. Using these data, weighted means and pooled standard deviations could be calculated to develop reference values and minimal detectable change scores that can be used in a clinical setting. These values can be used to inform patients about their functional level in reference to the performance of a population and may help to identify those patients who will benefit from early intervention.

\section{METHODS}

A search was conducted in the PubMed and the Cumulative Index of Allied Health Literature (CINAHL) databases using the search terms "walking speed OR gait speed." Inclusion and exclusion criteria for articles can be found in Table 1. Abstracts and titles were reviewed to determine relevance. Full-text, portable document format (PDF) articles were obtained for further review if gait speed measurements were collected in subjects between 70 and 79 years of age. Reference lists of appropriate studies were also examined to locate additional studies.

During the course of data collection, two systematic reviews were identified in which the authors investigated walking speed in older adults. 3,5 These articles were used to locate additional studies. If primary study authors did not report data separately for males and females, means and standard deviations (SD) reported in the meta-analysis by Bohannon et al were used. ${ }^{5}$ Similarly, if authors did not report data separately for the age group used for inclusion, means and SD reported by Bohannon et al were used. ${ }^{5}$ Means, SD, and number of subjects were obtained from or calculated for each dataset and entered into two Microsoft Excel spreadsheets - one for males and one for females. The main author, country of study, and timing method were also included in the spreadsheet. 


\section{Procedure for Calculating the Weighted Mean}

From each article, the arithmetic mean was obtained. The weighted mean was calculated as the overall sum of individual scores divided by the number of scores from all subjects. The formula for calculating the weighted mean can be found in Equation 1.51

\begin{tabular}{|l|l|}
\hline (1) & $\bar{X}=\frac{\sum x}{n} \Rightarrow \sum x=(\bar{X})(n)$ \\
\hline
\end{tabular}

\section{Procedure for Calculating the Weighted Standard Deviation using the Inverse Variance Method}

Standard deviations were obtained for each group. The variance was calculated as the square of the standard deviation. The inverse of the variance (one over the variance) was then calculated. The average of all the inverse variance (average inverse variance) was calculated. The inverse of the "average inverse variance" was then calculated. The square root of the inverse of the "average inverse variance" was calculated and defined as the weighted standard deviation. The formula for calculating the weighted standard deviation can be found in Equation 2.52

(2) $\quad$ weighted $S D=\left(\frac{1}{\frac{\sum \frac{1}{\sigma^{2}}}{n}}\right)^{.5}$

Procedure for Determining the Percentile Rank Value

The formula for calculating $z$ values from means and standard deviations (Equation 3) was used to determine percentile ranks. Equation 4 is a transformation of Equation 3. Percentile values from 5 to 95 were calculated using the area under the normal curve associated with percentiles .05 to .45 below and above the mean at intervals of .05 .

\begin{tabular}{|l|l|}
\hline (3) & $z=\frac{X-\bar{X}}{s d}$ \\
\hline
\end{tabular}

\begin{tabular}{|l|l|}
\hline (4) & $X=[(z)(s d)]+\bar{X}$ \\
\hline
\end{tabular}

\section{Procedure for Calculating Minimal Detectable Change}

Minimal Detectable Change (MDC) was calculated using a $z$ value of 1.96 for a $95 \%$ confidence level and a $z$ value of 1.65 for a $90 \%$ confidence level, with Equation 5. Intra-rater correlation coefficients reported by Peters et al. were used for calculating the MDC. ${ }^{48}$

\begin{tabular}{|l|l|}
\hline (5) & $M D C=Z \cdot \sqrt{2} \cdot(S D) \cdot(\sqrt{1-I C C}$ \\
\hline
\end{tabular}


Table 1. Inclusion and Exclusion Criteria for Articles

\begin{tabular}{|l|l|}
\hline \multicolumn{2}{|l|}{ Inclusion Criteria } \\
\hline & • Walking speed described as "comfortable," "preferred," "usual," "normal" or "self-selected" pace \\
\hline & • Subjects were between 70 and 79 years of age \\
\hline & • Subjects were classified as community-dwelling, healthy individuals \\
\hline & • English-language \\
\hline & • Means, standard deviation, and counts (n) were either presented or were easily discerned from the values reported. \\
\hline & • Data for males and females were reported separately \\
\hline Exclusion Criteria \\
\hline & • Sampling methods or testing protocol were not well described by the authors. \\
\hline & • Data for 70 to 79 year old subjects were not reported separately. \\
\hline
\end{tabular}

\section{RESULTS}

The countries of origin of studies for females between 70 and 79 years and number of subjects can be found in Table 2. The overall mean for comfortable walking speed in females was $105.49 \mathrm{~cm} / \mathrm{sec}$ with $S D+21.20 \mathrm{~cm} / \mathrm{sec}$, based on a sample of 12393 subjects. The most common device used for measuring walking speed was a stopwatch (68\%), followed by a gait mat (18\%), and a timing unit (15\%). Studies from the United States were most common (48\%), followed by Australia (12\%), Japan (9\%), and Sweden (9\%). Subjects from the United States represented $70 \%$ of the total sample used for analysis, followed by Spain with $10 \%$. There was no predominant protocol for the distance of the walking course; some authors used the six-meter walk test while others used the 30-meter walk test or the 10-meter walk test. Authors who used the gait mat were limited in distance walked by the length of the mat. Appendix A lists the studies for females used for analysis, along with the principle author, country of origin, measuring device used for collecting data, mean, SD, and the count (n). The $1^{2}$ statistic indicated that the mean walking speeds across articles were, indeed, heterogeneous.

The countries of origin of studies for males between 70 and 79 years and number of subjects can be found in Table 3 . The overall mean for comfortable walking speed in males was $116.72 \mathrm{~cm} / \mathrm{sec}$ with a SD of $\pm 18.77 \mathrm{~cm} / \mathrm{sec}$, based on a sample of 6359 subjects. For the studies in the analysis, the most common device used for measuring walking speed was a stopwatch $(73 \%)$, followed by a gait mat $(15 \%)$, and a timing unit $(12 \%)$. Again, studies from the United States were the most frequent $(45 \%)$, followed by Sweden (14\%). Subjects from the United States represented $67 \%$ of the total sample used for analysis, followed by China - Hong Kong with 11\%. Again, there was no predominant protocol for the distance of the walking course.

Percentile ranks calculated from the area under the curve for the Gaussian distribution can be found in Table 4. Minimal Detectable Changes (MDC) was calculated using a $z$ value of 1.96 for a $95 \%$ confidence level and a $z$ value of 1.65 for a $90 \%$ confidence level. The test-retest reliability coefficient of .97 was used based on the values reported by Peters et al. ${ }^{48} \mathrm{For}$ females, the $\mathrm{MDC}_{95}$ was $10.18 \mathrm{~cm} / \mathrm{sec}$, while the $\mathrm{MDC}_{90}$ was $8.57 \mathrm{~cm} / \mathrm{sec}$. For males, the $\mathrm{MDC}_{95}$ was $9.01 \mathrm{~cm} / \mathrm{sec}$, while the MDC 90 was $7.59 \mathrm{~cm} / \mathrm{sec}$.

Table 2. Country of Origin of Studies for Females Between 70 And 79 Years and Number of Subjects

\begin{tabular}{|l|r|r|}
\hline Country & Studies & Subjects \\
\hline Australia & 4 & 402 \\
\hline Canada & 1 & 14 \\
\hline Germany & 1 & 106 \\
\hline Holland & 1 & 41 \\
\hline China - Hong Kong & 1 & 665 \\
\hline Israel & 1 & 11 \\
\hline Italy & 1 & 253 \\
\hline Japan & 3 & 446 \\
\hline Spain & 1 & 1226 \\
\hline Sweden & 3 & 223 \\
\hline Thailand & 1 & 329 \\
\hline United States & 16 & 8677 \\
\hline TOTAL & 33 & 12393 \\
\hline
\end{tabular}


Table 3. Country of Origin of Studies for Males Between 70 and 79 Years and Number of Subjects

\begin{tabular}{|l|r|r|}
\hline Country & Studies & Subjects \\
\hline Australia & 2 & 177 \\
\hline Germany & 1 & 141 \\
\hline Holland & 1 & 17 \\
\hline China - Hong Kong & 1 & 708 \\
\hline Italy & 1 & 213 \\
\hline Japan & 1 & 219 \\
\hline Spain & 1 & 370 \\
\hline Sweden & 3 & 190 \\
\hline Thailand & 1 & 180 \\
\hline United States & 10 & 4144 \\
\hline Total & 22 & 6359 \\
\hline & & \\
\hline
\end{tabular}

Table 4. Percentile Ranks for Walking Speed for Community-Dwelling Males ( $\mathrm{N}=6359)$ and Females ( $\mathrm{N}=12393)$ Age 70-79 Years

\begin{tabular}{|c|c|c|c|c|c|c|c|}
\hline & \multicolumn{3}{|c|}{ Males } & & \multicolumn{3}{c|}{ Females } \\
\hline Percentile Rank & $\mathbf{c m} / \mathbf{s e c}$ & $\mathbf{m} / \mathbf{s e c}$ & $\mathbf{M P H}$ & & $\mathbf{c m} / \mathbf{s e c}$ & $\underline{\mathbf{m} / \mathbf{s e c}}$ & $\mathbf{M P H}$ \\
\hline 90 & 140.77 & 1.41 & 3.15 & & 132.66 & 1.33 & 2.97 \\
\hline 85 & 136.17 & 1.36 & 3.05 & & 127.46 & 1.27 & 2.85 \\
\hline 80 & 132.52 & 1.33 & 2.96 & & 123.33 & 1.23 & 2.76 \\
\hline 75 & 129.38 & 1.29 & 2.89 & & 119.79 & 1.20 & 2.68 \\
\hline 70 & 126.56 & 1.27 & 2.83 & & 116.61 & 1.17 & 2.61 \\
\hline 65 & 123.95 & 1.24 & 2.77 & & 113.66 & 1.14 & 2.54 \\
\hline 60 & 121.48 & 1.21 & 2.72 & & 110.86 & 1.11 & 2.48 \\
\hline 55 & 119.08 & 1.19 & 2.66 & & 108.15 & 1.08 & 2.42 \\
\hline 50 & 116.72 & 1.17 & 2.61 & & 105.49 & 1.05 & 2.36 \\
\hline 45 & 114.36 & 1.14 & 2.56 & & 102.83 & 1.03 & 2.30 \\
\hline 40 & 111.96 & 1.12 & 2.50 & & 100.12 & 1.00 & 2.24 \\
\hline 35 & 109.49 & 1.09 & 2.45 & & 97.32 & 0.97 & 2.18 \\
\hline 30 & 106.88 & 1.07 & 2.39 & & 94.37 & 0.94 & 2.11 \\
\hline 25 & 104.06 & 1.04 & 2.33 & & 91.19 & 0.91 & 2.04 \\
\hline 20 & 100.92 & 1.01 & 2.26 & & 87.65 & 0.88 & 1.96 \\
\hline 15 & 97.27 & 0.97 & 2.18 & & 83.52 & 0.84 & 1.87 \\
\hline 10 & 92.67 & 0.93 & 2.07 & & 78.32 & 0.78 & 1.75 \\
\hline 5 & 85.84 & 0.86 & 1.92 & & 70.61 & 0.71 & 1.58 \\
\hline
\end{tabular}

\section{DISCUSSION}

It was the objective of this meta-analysis to establish normative reference values and minimal detectable change for comfortable walking speed in community-dwelling, older adults between 70 and 79 years of age. Data used in this meta-analysis were collected from 33 studies and 11 countries. The use of a culturally and racially diverse pool of studies makes the findings applicable to a very broad population. Researchers have used different terms to describe comfortable walking speed, including habitual, self-selective, normal, preferred and usual. ${ }^{4-47}$ Walking speed is easily measured, time efficient, cost effective, and requires minimal equipment, making it a useful and feasible clinical outcome measure for the evaluation, examination, and development of interventions for patients and clients in the physical therapy setting. It has even been referred to as the sixth vital sign. ${ }^{4}$ 
The results of our calculations show that the weighted mean for normal walking speed in females is $105.67 \mathrm{~cm} / \mathrm{sec}$ with a pooled standard deviation of $21.45 \mathrm{~cm} / \mathrm{sec}$, and the weighted mean for normal walking speed in males is $116.94 \mathrm{~cm} / \mathrm{sec}$ with a pooled standard deviation of $18.73 \mathrm{~cm} / \mathrm{sec}$. Bohannon et al suggested a normal walking speed of $113.20 \mathrm{~cm} / \mathrm{sec}$ for females and 126.20 $\mathrm{cm} / \mathrm{sec}$ for males. ${ }^{5}$ However, he did not provide estimates of variation, which are required to calculate reference values. Brach et al indicated that normal walking speed for males and females combined was approximately $1.07 \mathrm{~m} / \mathrm{sec}(107 \mathrm{~cm} / \mathrm{sec}) .{ }^{13}$

Pedrero-Chamizo et al reported reference values for comfortable walking speed among only non-institutionalized, older adults in Spain. Their sample size was considerably smaller than that used in the present analysis (329 males and 1183 females between the ages of 70 and 79 years). ${ }^{31}$ The current analysis includes 12064 females and 6179 males. The comfortable walking speed reported by Pedrero-Chamizo et al was $163.82 \mathrm{~cm} / \mathrm{sec}$ for females and $189.07 \mathrm{~cm} / \mathrm{sec}$ for males. They used only a 30-meter walking course to measure walking speed and calculated their percentile ranks in units of time (sec). ${ }^{31}$ These authors provided few details of their methodology for measuring walking speed, and it is not obvious why their results differ so much from average walking speed across studies in the aggregate.

Among the studies incorporated in the current analysis, distances used to measure walking speed ranged between $3.66 \mathrm{~m}(12$ feet) and $30 \mathrm{~m}$ (98 feet). Graham et al examined the prevalence of walking speed protocols used in a variety of subject populations. ${ }^{46}$ They noted that authors most commonly instructed subjects to walk at a usual or normal speed. Some authors included acceleration and deceleration phases in their walking course (dynamic starts) while others did not include any phases (static or standing starts). They also noted that distances of 10 meters, 6 meters, and 4 meters were commonly cited; however, 10-meter courses were most commonly used. ${ }^{46}$

We reported the $\mathrm{MDC}_{95}$ and $\mathrm{MDC}_{90}$ for females at $10.18 \mathrm{~cm} / \mathrm{sec}$ and $8.57 \mathrm{~cm} / \mathrm{sec}$, respectively; for males, $\mathrm{MDC}_{95}$ and $\mathrm{MDC}_{90}$ were $9.01 \mathrm{~cm} / \mathrm{sec}$ and $7.59 \mathrm{~cm} / \mathrm{sec}$, respectively. Peters et al reported $M C_{95}$ and $M D C_{90}$ between 0.01 to $0.02 \mathrm{~m} / \mathrm{sec}(1.00$ to $2.00 \mathrm{~cm} / \mathrm{sec})^{48}$; whereas, Puthoff and Saskowski reported a MDC 95 of $0.16 \mathrm{~m} / \mathrm{sec}(1.6 \mathrm{~cm} / \mathrm{sec}) .^{53}$ Neither Peters et al or Puthoff and Saskowski categorized MDC according to sex. ${ }^{48,53}$ We reported separate MDC for each sex. We also believe much of the discrepancies in MDC may be due to precision of measurement, as $\mathrm{cm} / \mathrm{sec}$ is more precise than $\mathrm{m} / \mathrm{sec}$.

No specific testing protocol was predominantly used in the studies included in this meta-analysis (see Appendix A). There are numerous devices for measuring walking speed, including stopwatches, gait mats, photography, radar, and timing devices. A stopwatch was used in approximately $68 \%$ of the studies included in our analysis. Although many researchers used a stopwatch to time the distance walked, there was no universal method for measuring time. Therefore, exclusion criteria were used to eliminate articles that did not have well-defined testing protocols.

There may be need for a discussion to establish standardized protocols for measuring walking speed to provide more consistent and homogenous data. As is obvious in Appendices A and B, mean walking speeds varied considerably across studies. A single standardized protocol will not suffice for use in clinical settings because the needs of the patient and the resources available to the clinician may change depending on the clinical setting. All methods that have been incorporated in the current analysis appear to be valid in the measurement of walking speed.

Harvill presented a method for calculating score bands as an indication of the normal variability of a measure ${ }^{54}$ Calculating score bands for normal walking speed is important in the prevention and wellness setting because it helps to estimate the true variability of a normal individual's ability. To determine score bands, means, standard deviations, and reliability coefficients must first be determined. The results of this study could be used to assist in the development of score bands for patients or clients as indicators of their medical status.

A limitation of this meta-analysis is the fact there were no consistent methods used to account for the morbidities that are found in older adults. Authors reported that the subjects in their studies were independent and community dwelling and did not address the different morbidities present unless they were studying a specific population defined by the morbidity. In those cases, subjects were selected if they met the specific inclusion criteria imposed by the author. We were interested in subjects who were described by the authors as independent and community dwelling, regardless of their morbidities.

\section{CONCLUSION}

Walking speed has been proposed as the sixth vital sign to be collected during routine healthcare visits. As is the case with the other vital signs (blood pressure, heart rate, respiratory rate, pain, and temperature), normal reference values for walking speed are necessary to interpret a patient's score. If the score is aberrant on the negative side, the clinician must note, and if potentially 
probative, explore the underlying reasons for this deviation from normality. A positive aberration, of course, may also be noteworthy. In either case, a deviation from normality requires defining what is "normal."

The weighted mean for walking speed in females between 70 and 79 years of age was $105.67 \mathrm{~cm} / \mathrm{sec}$ with a pooled standard deviation of $21.45 \mathrm{~cm} / \mathrm{sec}$ and the weighted mean for walking speed in males was $116.94 \mathrm{~cm} / \mathrm{sec}$ with a pooled standard deviation of $18.73 \mathrm{~cm} / \mathrm{sec}$. The $\mathrm{MDC}_{95}$ and $\mathrm{MDC}_{90}$ for females were $10.18 \mathrm{~cm} / \mathrm{sec}$ and $8.57 \mathrm{~cm} / \mathrm{sec}$, respectively. The MDC 95 and $\mathrm{MDC}_{90}$ for males were $9.01 \mathrm{~cm} / \mathrm{sec}$ and $7.59 \mathrm{~cm} / \mathrm{sec}$, respectively. From these results, it was possible to develop normal reference values that can be used in a clinical setting for examination, evaluation, and development of a plan of care. Normal reference values were translated into percentile ranks, which are easy to explain and easy to understand. In terms of future directions for this area of study, the calculation of score bands is also necessary to determine the natural variability of scores in walking speed in patients and clients.

\section{REFERENCES}

1. World Health Organization. International Classification of Functioning, Disability and Health (ICF). Geneva, Switzerland: World Health Organization; 2001.

2. Bohannon RW, Williams Andrews A. Normal walking speed: a descriptive meta-analysis. Physiotherapy. 2011 Sep;97(3):182-9. [PMID: 21820535]

3. Rydwik E, Bergland A, Forsen L, Frandin K. Investigation into the reliability and validity of the measurement of elderly people's clinical walking speed: a systematic review. Physiother Theory Pract. 2012 Apr;28(3):238-56. [PMID: 21929322]

4. $\quad$ Fritz S, Lusardi M. White paper: "walking speed: the sixth vital sign". J Geriatr Phys Ther. 2009;32(2):46-9. [PMID: 20039582]

5. Bohannon RW, Andrews AW, Thomas MW. Walking speed: reference values and correlates for older adults. J Orthop Sports Phys Ther. 1996 Aug;24(2):86-90. [PMID: 8832471]

6. Woo J, Ho SC, Yu AL. Walking speed and stride length predicts 36 months dependency, mortality, and institutionalization in Chinese aged 70 and older. J Am Geriatr Soc. 1999 Oct;47(10):1257-60. [PMID: 10522962]

7. Studenski S, Perera S, Wallace D, Chandler JM, Duncan PW, Rooney E, Fox M, Guralnik JM. Physical performance measures in the clinical setting. J Am Geriatr Soc. 2003 Mar;51(3):314-22. [PMID: 12588574]

8. Aniansson A, Rundgren A, Sperling L. Evaluation of functional capacity in activities of daily living in 70-year-old men and women. Scand J Rehabil Med. 1980;12(4):145-54. [PMID: 7268322]

9. Aoyagi K, Ross PD, Nevitt MC, Davis JW, Wasnich RD, Hayashi T, Takemoto T. Comparison of performance-based measures among native Japanese, Japanese-Americans in Hawaii and Caucasian women in the United States, ages 65 years and over: a cross-sectional study. BMC Geriatr. 2001;1:3. [PMID: 11696243]

10. Arnadottir SA, Mercer VS. Effects of footwear on measurements of balance and gait in women between the ages of 65 and 93 years. Phys Ther. 2000 Jan;80(1):17-27. [PMID: 10623957]

11. Atkinson HH, Rosano C, Simonsick EM, Williamson JD, Davis C, Ambrosius WT, Rapp SR, Cesari M, Newman AB, Harris TB, Rubin SM, Yaffe K, Satterfield S, Kritchevsky SB. Cognitive function, gait speed decline, and comorbidities: the health, aging and body composition study. J Gerontol A Biol Sci Med Sci. 2007 Aug;62(8):844-50. [PMID: 17702875]

12. Ble A, Volpato S, Zuliani G, Guralnik JM, Bandinelli S, Lauretani F, Bartali B, Maraldi C, Fellin R, Ferrucci L. Executive function correlates with walking speed in older persons: the InCHIANTI study. J Am Geriatr Soc. 2005 Mar;53(3):410-5. [PMID: 15743282]

13. Brach JS, Studenski SA, Perera S, VanSwearingen JM, Newman AB. Gait variability and the risk of incident mobility disability in community-dwelling older adults. J Gerontol A Biol Sci Med Sci. 2007 Sep;62(9):983-8. [PMID: 17895436]

14. Carvalho $C$, Sunnerhagen KS, Willen $C$. Walking speed and distance in different environments of subjects in the later stage post-stroke. Physiother Theory Pract. 2010 Nov;26(8):519-27. [PMID: 20649494]

15. Cesari M, Kritchevsky SB, Penninx BW, Nicklas BJ, Simonsick EM, Newman AB, Tylavsky FA, Brach JS, Satterfield S, Bauer DC, Visser M, Rubin SM, Harris TB, Pahor M. Prognostic value of usual gait speed in well-functioning older people-results from the Health, Aging and Body Composition Study. J Am Geriatr Soc. 2005 Oct;53(10):1675-80. [PMID: 16181165]

16. Cyarto EV, Myers A, Tudor-Locke C. Pedometer accuracy in nursing home and community-dwelling older adults. Med Sci Sports Exerc. 2004 Feb;36(2):205-9. [PMID: 14767241]

17. DePasquale L, Toscano L. The Spring Scale Test: a reliable and valid tool for explaining fall history. $J$ Geriatr Phys Ther. 2009;32(4):159-67. [PMID: 20469565]

18. Freiberger E, Menz HB, Abu-Omar K, Rutten A. Preventing falls in physically active community-dwelling older people: a comparison of two intervention techniques. Gerontology. 2007;53(5):298-305. [PMID: 17536207]

19. Hardy SE, Perera S, Roumani YF, Chandler JM, Studenski SA. Improvement in usual gait speed predicts better survival in older adults. J Am Geriatr Soc. 2007 Nov;55(11):1727-34. [PMID: 17916121]

20. Laufer Y. Age- and gender-related changes in the temporal-spatial characteristics of forwards and backwards gaits. Physiother Res Int. 2003;8(3):131-42. [PMID: 14533369] 
21. Lindsey C, Brownbill RA, Bohannon RA, llich JZ. Association of physical performance measures with bone mineral density in postmenopausal women. Arch Phys Med Rehabil. 2005 Jun;86(6):1102-7. [PMID: 15954047]

22. Lord SR, Lloyd DG, Li SK. Sensori-motor function, gait patterns and falls in community-dwelling women. Age Ageing. 1996 Jul;25(4):292-9. [PMID: 8831874]

23. Nagasaki $\mathrm{H}$, Itoh $\mathrm{H}$, Hashizume $\mathrm{K}$, Furuna $\mathrm{T}$, Maruyama $\mathrm{H}$, Kinugasa $\mathrm{T}$. Walking patterns and finger rhythm of older adults. Percept Mot Skills. 1996 Apr;82(2):435-47. [PMID: 8724913]

24. Palombaro KM, Craik RL, Mangione KK, Tomlinson JD. Determining meaningful changes in gait speed after hip fracture. Phys Ther. 2006 Jun;86(6):809-16. [PMID: 16737406]

25. Taaffe DR, Simonsick EM, Visser M, Volpato S, Nevitt MC, Cauley JA, Tylavsky FA, Harris TB. Lower extremity physical performance and hip bone mineral density in elderly black and white men and women: cross-sectional associations in the Health ABC Study. J Gerontol A Biol Sci Med Sci. 2003 Oct;58(10):M934-42. [PMID: 14570862]

26. Tiedemann A, Sherrington C, Lord SR. Physiological and psychological predictors of walking speed in older communitydwelling people. Gerontology. 2005 Nov-Dec;51(6):390-5. [PMID: 16299420]

27. van lersel MB, Olde Rikkert MG, Borm GF. A method to standardize gait and balance variables for gait velocity. Gait Posture. $2007 \mathrm{Jul} ; 26(2): 226-30$. [PMID: 17035022]

28. Willen C, Sunnerhagen KS, Ekman C, Grimby G. How is walking speed related to muscle strength? A study of healthy persons and persons with late effects of polio. Arch Phys Med Rehabil. 2004 Dec;85(12):1923-8. [PMID: 15605327]

29. Wolfson L, Whipple R, Derby C, Judge J, King M, Amerman P, Schmidt J, Smyers D. Balance and strength training in older adults: intervention gains and Tai Chi maintenance. J Am Geriatr Soc. 1996 May;44(5):498-506. [PMID: 8617896]

30. Kamide N, Shiba Y, Koide K, Haga H, Shibata H. The Timed Up and Go Test is Related to Quantitative Ultrasound Parameters of Bone Strength in Japanese Community-Dwelling Elderly Women. J of Phys Ther Sci. 2009;21(4):373-8.

31. Pedrero-Chamizo R, Gomez-Cabello A, Delgado S, Rodriguez-Llarena S, Rodriguez-Marroyo JA, Cabanillas E, Melendez A, Vicente-Rodriguez G, Aznar S, Villa G, Espino L, Gusi N, Casajus JA, Ara I, Gonzalez-Gross M. Physical fitness levels among independent non-institutionalized Spanish elderly: the elderly EXERNET multi-center study. Arch Gerontol Geriatr. 2012 Sep-Oct;55(2):406-16. [PMID: 22424779]

32. Thaweewannakij T, Wilaichit S, Chuchot R, Yuenyong Y, Saengsuwan J, Siritaratiwat W, Amatachaya S. Reference Values of Physical Performance in Well-Functioning, Community-Dwelling Thai Elderly People. Phys Ther. 2013 Apr 25. [PMID: 23620530]

33. Lusardi M, Pellecchia G, Schulman M. Functional Performance in Community Living Older Adults. J Geriatr Phys Ther. 2003;26(3):14-22.

34. Mosallanezhad Z, Horder H, Salavati M, Nilsson-Wikmar L, Frandin K. Physical activity and physical functioning in Swedish and Iranian 75-year-olds - a comparison. Arch Gerontol Geriatr. 2012 Sep-Oct;55(2):422-30. [PMID: 22425242]

35. von Bonsdorff M, Rantanen T, Laukkanen $P$, Suutama $T$, Heikkinen E. Mobility limitations and cognitive deficits as predictors of institutionalization among community-dwelling older people. Gerontology. 2006;52(6):359-65. [PMID: 16905887]

36. Purser JL, Pieper CF, Poole C, Morey M. Trajectories of leg strength and gait speed among sedentary older adults: longitudinal pattern of dose response. J Gerontol A Biol Sci Med Sci. 2003 Dec;58(12):M1125-34. [PMID: 14684710]

37. Guimaraes RM, Isaacs B. Characteristics of the gait in old people who fall. Int Rehabil Med. 1980;2(4):177-80. [PMID: 7239777]

38. Hill K, Scjwarz J, Flicker L, Carroll S. Falls among healthy, community-dwelling, older women: a prospective study of frequency, circumstances, consequences and prediction accuracy. Aust N Z J Public Health. 1999 Feb;23(1):41-8.

39. Steffen TM, Hacker TA, Mollinger L. Age- and gender-related test performance in community-dwelling elderly people: SixMinute Walk Test, Berg Balance Scale, Timed Up \& Go Test, and gait speeds. Phys Ther. 2002 Feb;82(2):128-37. [PMID: 11856064]

40. Lundgren-Lindquist B, Aniansson A, Rundgren A. Functional studies in 79-year-olds. III. Walking performance and climbing capacity. Scand J Rehabil Med. 1983;15(3):125-31. [PMID: 6635602]

41. Leiper $\mathrm{Cl}$, Craik RL. Relationships between physical activity and temporal-distance characteristics of walking in elderly women. Phys Ther. 1991 Nov;71(11):791-803. [PMID: 1946617]

42. Bohannon RW. Comfortable and maximum walking speed of adults aged 20-79 years: reference values and determinants. Age Ageing. 1997 Jan;26(1):15-9. [PMID: 9143432]

43. Callisaya M, Blizzard L, Schmidt M, McGinley J, Srikanth V. Sex modifies the relationship between age and gait: a population-based study of older adults. J Gerontol A Biol Sci Med Sci. 2008 Feb;63(2):165-70. [PMID: 18314452]

44. Cooper R, Kuh D, Hardy R. Objectively measured physical capability levels and mortality: systematic review and metaanalysis. BMJ. 2010;341:c4467. [PMID: 20829298]

45. Oberg T, Karsznia A, Oberg K. Basic gait parameters: reference data for normal subjects, $10-79$ years of age. J Rehabil Res Dev. 1993;30(2):210-23. [PMID: 8035350] 
46. Graham JE, Ostir GV, Kuo YF, Fisher SR, Ottenbacher KJ. Relationship between test methodology and mean velocity in timed walk tests: a review. Arch Phys Med Rehabil. 2008 May;89(5):865-72. [PMID: 18452733]

47. Fitzpatrick AL, Buchanan CK, Nahin RL, Dekosky ST, Atkinson HH, Carlson MC, Williamson JD. Associations of gait speed and other measures of physical function with cognition in a healthy cohort of elderly persons. J Gerontol A Biol Sci Med Sci. 2007 Nov;62(11):1244-51. [PMID: 18000144]

48. Peters DM, Fritz SL, Krotish DE. Assessing the reliability and validity of a shorter walk test compared with the 10-Meter Walk Test for measurements of gait speed in healthy, older adults. J Geriatr Phys Ther. 2013 Jan-Mar;36(1):24-30. [PMID: 22415358]

49. Ries JD, Echternach JL, Nof L, Gagnon Blodgett M. Test-retest reliability and minimal detectable change scores for the timed "up \& go" test, the six-minute walk test, and gait speed in people with Alzheimer disease. Phys Ther. 2009 Jun;89(6):569-79. [PMID: 19389792]

50. Weir JP. Quantifying test-retest reliability using the intraclass correlation coefficient and the SEM. J Strength Cond Res. 2005 Feb;19(1):231-40. [PMID: 15705040]

51. Hinkle D, Wiersma W, Jurs S. Applied Statistics for the Behavior Sciences. 5th ed. Boston: Houghton Mifflin Co.; 2003.

52. Borenstein M, hedges LV, Higgins JP, Rothstein HR. Generality of the Basic Inverse-Variance Method, in Introduction to Meta-Analysis. Chichester, UK: John Wiley \& Sons, Ltd.; 2009.

53. Puthoff ML, Saskowski D. Reliability and responsiveness of gait speed, five times sit to stand, and hand grip strength for patients in cardiac rehabilitation. Cardiopulm Phys Ther J. Mar;24(1):31-7. [PMID: 23754937]

54. Harvill L. Standard Error of Measurement. Educational Measurement: Issues and Practice. 1991;10(2):181-9. 
APPENDIX A

List of Studies for Females Used for Analysis with Principle Author, Country, Measuring Device, Mean, SD, and n

\begin{tabular}{|c|c|c|c|c|c|}
\hline Author & Country & Device & $\begin{array}{c}\text { Mean } \\
\text { (cm/sec) }\end{array}$ & SD & $\mathrm{n}$ \\
\hline Lord22 & Australia & Timer & 107.00 & 17.00 & 22 \\
\hline Lord22 & Australia & Timer & 101.00 & 19.00 & 26 \\
\hline Tiedeman 26 & Australia & Stopwatch & 110.80 & 19.90 & 225 \\
\hline Hill 38 & Australia & Stopwatch & 116.30 & 66.80 & 60 \\
\hline Hill|38 & Australia & Stopwatch & 109.20 & 77.80 & 27 \\
\hline Callisaya 43 & Australia $(70-74)$ & Gait mat & 121.93 & 19.17 & 15 \\
\hline Callisaya ${ }^{43}$ & Australia (75 - 79) & Gait mat & 104.41 & 16.41 & 27 \\
\hline Cyarto $^{16}$ & Canada & Timer & 122.00 & 18.00 & 14 \\
\hline Freiberger ${ }^{18}$ & Germany & Stopwatch & 129.90 & 25.20 & 106 \\
\hline Van lersel ${ }^{27}$ & Holland & Gait Mat & 150.00 & 18.70 & 41 \\
\hline Woo 6 & Hong Kong (70-75) & Stopwatch & 92.16 & 13.84 & 665 \\
\hline Laufer20 & Israel & Gait Mat & 96.20 & 27.20 & 11 \\
\hline $\mathrm{Ble}^{12}$ & Italy & Timer & 94.70 & 25.60 & 253 \\
\hline Aoyagi ${ }^{9}$ & Japan (70-74) & Stopwatch & 99.00 & 30.36 & 50 \\
\hline Aoyagi9 & Japan (75-79) & Stopwatch & 89.00 & 30.30 & 19 \\
\hline Kamide $^{30}$ & Japan & Stopwatch & 135.00 & 22.00 & 56 \\
\hline Nagasaki23 & Japan & Stopwatch & 97.00 & 23.20 & 108 \\
\hline Nagasaki23 & Japan & Stopwatch & 103.80 & 27.00 & 213 \\
\hline Pedrero-Chamizo ${ }^{31}$ & Spain (70-74) & Stopwatch & 166.67 & 21.29 & 724 \\
\hline Pedrero-Chamizo ${ }^{31}$ & Spain (75-79) & Stopwatch & 158.73 & 31.59 & 502 \\
\hline Oberg45 & Sweden & Timer & 110.00 & 12.00 & 15 \\
\hline Aniansson ${ }^{13}$ & Sweden & Stopwatch & 110.00 & 20.00 & 194 \\
\hline Willen ${ }^{28}$ & Sweden & Stopwatch & 116.00 & 23.00 & 14 \\
\hline Thaweewannakij32 & Thailand & Stopwatch & 99.00 & 15.00 & 329 \\
\hline DePaasquale ${ }^{17}$ & USA & Stopwatch & 117.50 & 18.00 & 10 \\
\hline Lusardi33 & USA & Gait Mat & 125.00 & 18.00 & 10 \\
\hline Purser $^{36}$ & USA & Stopwatch & 108.90 & 18.30 & 48 \\
\hline Brach $^{13}$ & USA & Gait Mat & 104.00 & 19.00 & 183 \\
\hline Wolfson 29 & USA & Timer & 113.20 & 19.10 & 26 \\
\hline Bohannon $1996^{5}$ & USA & Stopwatch & 134.30 & 19.60 & 21 \\
\hline Leiper $^{41}$ & USA & Gait Mat & 97.00 & 21.00 & 35 \\
\hline Atkinson ${ }^{11}$ & USA & Stopwatch & 111.00 & 21.00 & 1229 \\
\hline Taaffe $^{25}$ & USA - female White & Stopwatch & 115.38 & 21.04 & 847 \\
\hline Taaffe 25 & USA - female Black & Stopwatch & 101.69 & 22.77 & 723 \\
\hline Bohannon 199742 & USA & Stopwatch & 127.20 & 21.10 & 20 \\
\hline Steffen 39 & USA & Stopwatch & 133.00 & 22.00 & 22 \\
\hline Bohannon $2008^{2}$ & USA & Stopwatch & 93.00 & 22.90 & 210 \\
\hline Fitzpatrick47 & USA & Stopwatch & 94.30 & 23.00 & 939 \\
\hline Arnadottir ${ }^{11}$ & USA & Stopwatch & 126.00 & 28.00 & 14 \\
\hline Lindsey21 & USA & Stopwatch & 136.00 & 28.00 & 34 \\
\hline Aoyagi9 & USA - Jap-Am (70-74) & Stopwatch & 112.00 & 33.66 & 273 \\
\hline Aoyagi $^{9}$ & USA - Am Cau (70-74) & Stopwatch & 90.00 & 38.69 & 2557 \\
\hline Aoyagi ${ }^{9}$ & USA - Am Cau (75-79) & Stopwatch & 83.00 & 36.18 & 1258 \\
\hline Aoyagi ${ }^{9}$ & USA - Jap-Am (75-79) & Stopwatch & 101.00 & 27.59 & 218 \\
\hline
\end{tabular}


APPENDIX B

List of Studies for Males Used for Analysis with Principle Author, Country, Measuring Device, Mean, SD, and n

\begin{tabular}{|c|c|c|c|c|c|}
\hline Author & Country & Device & $\begin{array}{c}\text { Mean } \\
\text { (cm/sec) }\end{array}$ & SD & $\mathrm{n}$ \\
\hline Brach $^{13}$ & USA & Gait Mat & 112.00 & 20.00 & 108 \\
\hline Callisaya 43 & Australia (75 - 79) & Gait mat & 108.60 & 21.97 & 26 \\
\hline Callisaya ${ }^{43}$ & Australia (70 - 74) & Gait mat & 113.69 & 12.45 & 27 \\
\hline Van lersel ${ }^{27}$ & Holland & Gait Mat & 140.70 & 13.10 & 17 \\
\hline Aniansson 8 & Sweden & Stopwatch & 120.00 & 20.00 & 160 \\
\hline Atkinson 11 & USA & Stopwatch & 120.00 & 21.00 & 1120 \\
\hline Bohannon $2008^{2}$ & USA & Stopwatch & 95.70 & 22.90 & 237 \\
\hline Bohannon $1996^{5}$ & USA & Stopwatch & 141.80 & 21.30 & 22 \\
\hline Bohannon 199742 & USA & Stopwatch & 133.00 & 19.60 & 22 \\
\hline Woo ${ }^{6}$ & Hong Kong (70-75) & Stopwatch & 101.35 & 11.66 & 708 \\
\hline Fitzpatrick ${ }^{47}$ & USA & Stopwatch & 98.90 & 20.10 & 1083 \\
\hline Freiberger ${ }^{18}$ & Germany & Stopwatch & 139.60 & 27.60 & 141 \\
\hline Nagasaki23 & Japan & Stopwatch & 110.50 & 26.50 & 84 \\
\hline Nagasaki²3 & Japan & Stopwatch & 118.00 & 24.30 & 135 \\
\hline Taaffe ${ }^{25}$ & USA - male white & Stopwatch & 125.00 & 20.11 & 927 \\
\hline Taaffe 25 & USA - male Black & Stopwatch & 109.10 & 26.26 & 544 \\
\hline Pedrero-Chamizo ${ }^{31}$ & Spain $(70-74)$ & Stopwatch & 193.55 & 28.57 & 214 \\
\hline Pedrero-Chamizo ${ }^{31}$ & Spain (75-79) & Stopwatch & 182.93 & 25.57 & 156 \\
\hline Purser ${ }^{36}$ & USA & Stopwatch & 119.80 & 14.70 & 28 \\
\hline Steffen 39 & USA & Stopwatch & 138.00 & 23.00 & 14 \\
\hline Tiedeman ${ }^{26}$ & Australia & Stopwatch & 115.60 & 24.90 & 124 \\
\hline Willen ${ }^{28}$ & Sweden & Stopwatch & 132.00 & 16.00 & 15 \\
\hline Thaweewannakij32 & Thailand & Stopwatch & 109.00 & 20.00 & 180 \\
\hline $\mathrm{Ble}^{12}$ & Italy & Timer & 106.80 & 23.90 & 213 \\
\hline Oberg45 & Sweden & Timer & 118.00 & 15.00 & 15 \\
\hline Wolfson'29 & USA & Timer & 123.20 & 16.30 & 39 \\
\hline
\end{tabular}

